\title{
Narrative review of the mechanism of natural products and scar formation in wound repair
}

\author{
Xiaoping Wan ${ }^{1,2,3}$, Yangyang Chen ${ }^{1,3}$, Funeng Geng ${ }^{4}$, Yongmei Sheng ${ }^{4}$, Fang Wang ${ }^{1,3}, J^{\prime n l i n}$ Guo $^{1,3}$ \\ ${ }^{1}$ Key Laboratory of Systematic Research of Distinctive Chinese Medicine Resources in Southwest China, Chengdu University of Traditional \\ Chinese Medicine, Chengdu, China; ${ }^{2}$ Innovative Institute of Chinese Medicine and Pharmacy, Chengdu University of Traditional Chinese Medicine, \\ Chengdu, China; ${ }^{3}$ Ministry of Education Key Laboratory of Standardization of Chinese Herbal Medicine, Chengdu University of Traditional \\ Chinese Medicine, Chengdu, China; ${ }^{4}$ Sichuan Key Laboratory of Medical American Cockroach, Chengdu, China \\ Contributions: (I) Conception and design: J Guo, F Geng, X Wan; (II) Administrative support: Y Chen; (III) Provision of study materials or patients: Y \\ Sheng; (IV) Collection and assembly of data: X Wan; (V) Data analysis and interpretation: F Wang; (VI) Manuscript writing: All authors; (VII) Final \\ approval of manuscript: All authors. \\ Correspondence to: Jinlin Guo. Key Laboratory of Systematic Research of Distinctive Chinese Medicine Resources in Southwest China, \\ Chengdu University of Traditional Chinese Medicine, Chengdu, China; Ministry of Education Key Laboratory of Standardization of Chinese \\ Herbal Medicine, Chengdu University of Traditional Chinese Medicine, Chengdu, China. Email: guo596@cdutcm.edu.cn; Funeng Geng. \\ Sichuan Key Laboratory of Medical American Cockroach, Chengdu, China, 1166 Liutai Avenue, Wenjiang District, Chengdu 611137, China. \\ Email: haoyishenggfn@126.com.
}

Background and Objective: Wound healing is a complex and multifactorial response to the disruption of the normal anatomy and function of skin tissue, which mainly includes four progressive stages: hemostasis, inflammation, proliferation and remodeling. Wound healing is a complex process, and multiple conditions can lead to impaired wound healing and, consequently, scar formation. Natural products discovered and applied for a long time have always been the source of new drugs. With the deepening of research, the role of natural products in promoting wound repair has gradually been a focus. Some natural products and compound drugs are effective in promoting skin wound healing and in reducing adverse reactions after wound healing.

Methods: This article reviews the mechanism of natural products and some compound drugs in healing skin wounds from the following aspects: related cellular effects during wound repair and scar formation, regulation of growth factors, extracellular matrix (ECM), and collagen metabolism.

Key Content and Findings: Proteolysis by proteolytic enzymes, such as plasmin, matrix metalloproteinases, and their activators and inhibitors, plays a critical role in wound repair. Some keratinocytes often express some matrix metalloproteinases and plasminogen activators, thus promoting the hydrolysis of components such as fibrin in blood clots to facilitate migration.

Conclusions: In this paper, we review recent studies on the role and mechanism of some natural products on scar formation found in wound repair. We aim to provide a basis for the in-depth study of the intrinsic mechanism of natural products in repairing wounds and a reference for further development of drugs for wound repair with better efficacy and fewer side effects.

Keywords: Wound repair; natural products; skin; scar formation

Submitted Dec 17, 2021. Accepted for publication Feb 21, 2022.

doi: 10.21037/atm-21-7046

View this article at: https://dx.doi.org/10.21037/atm-21-7046 


\section{Introduction}

The skin is the largest organ of the human body, accounting for approximately $16 \%$ of the total body weight (1). This organ is often injured due to physical or chemical factors, resulting in wounds. Wound healing is a complex and multifactorial response to the disruption of the normal anatomy and function of skin tissue, which mainly includes four progressive stages: hemostasis, inflammation, proliferation and remodeling (2). This process involves numerous cell types, extracellular matrix (ECM), and soluble mediators; cell differentiation, migration, and proliferation are key to repairing the integrity of injured tissues (3). The key to promote wound repair and reduce wound discomfort and scars is to avoid infection (4). At present, drugs for wound repair have been analyzed for their antiinflammatory, antibacterial, and antiseptic properties (5), and based on these findings, many clinical drugs for local wounds have been developed, such as platelet-rich plasma gel. However, most drugs appear to have simple active components with pharmacological effects and may have certain side effects on the body $(6,7)$, hence the need for drugs for wound repair with better efficacy and fewer side effects.

Natural products have long been the source of new drug discovery and development and, therefore, are also the main source of clinical drugs. Some studies have indicated that some natural plants can produce short chain peptides with smaller molecular weights in vivo, that is, plant defensins. Plant defensins are peptides that are widely distributed in plants and have significant antifungal activity, a wide antibacterial spectrum, and a strong resistance to pathogens $(8,9)$. Based on an early report on fibroblast growth in human umbilical vein endothelial cells as well as muscle and skin tissues, peptides were found to be effective in promoting mitosis of cells, thereby increasing the number of fibroblasts in muscle and skin tissues (10). Among natural products, propolis, ectoine and its derivatives, aloe, and arteannuin can promote tissue repair and achieve good results, showing anti-inflammatory, antibacterial, and antioxidant activities (11-14). In this paper, we review recent studies on the role and mechanism of some natural products on scar formation found in wound repair and point out future research directions, thus providing a reference for further study on natural products for wound repair (Figure 1).

We present the following article in accordance with the Narrative Review reporting checklist (available at https:// atm.amegroups.com/article/view/10.21037/atm-21-7046/rc).

\section{Methods}

This article reviews recent studies on the role and mechanism of some natural products on scar formation found in wound repair and point out future research directions, thus providing a reference for further study on natural products for wound repair. The search strategy summary as shown in Table 1.

\section{Mechanism of natural products in repairing wounds}

\section{Anti-inflammation and antibacterial effects}

Plant defensins are short chain peptides widely found in natural products that show antibacterial effects. They can interact with fungal-specific plasma membrane components

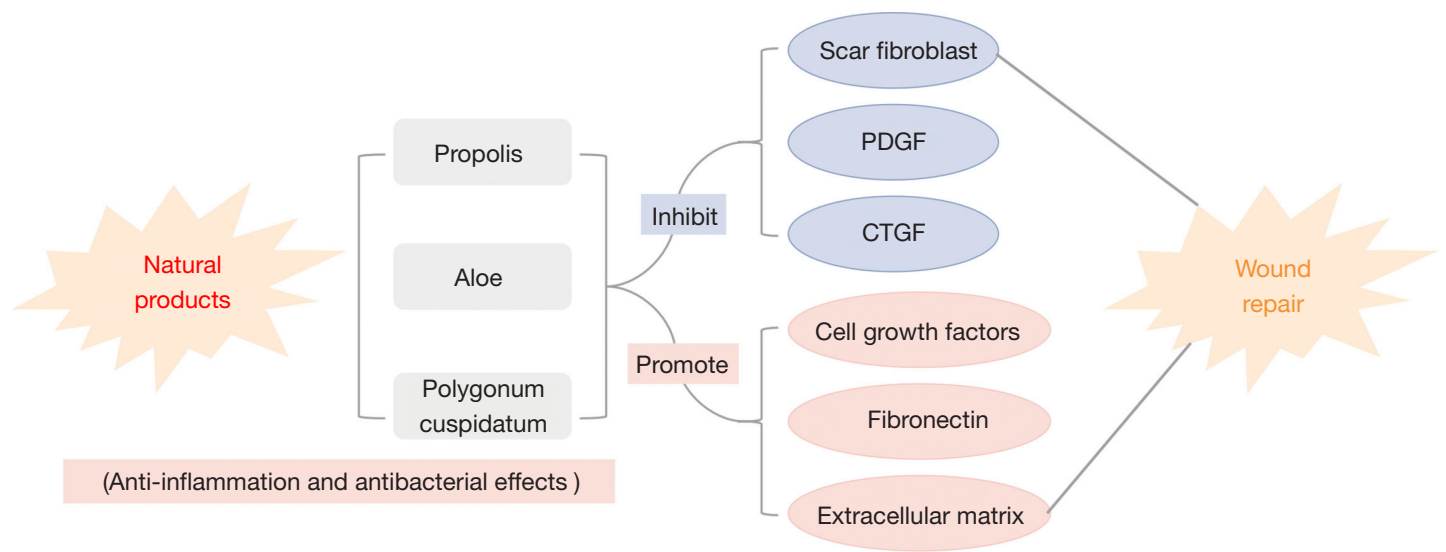

Figure 1 Wound healing is a complex process, and multiple conditions can lead to impaired wound healing and, consequently, scar formation. Natural products discovered and applied for a long time have always been the source of new drugs. 
Table 1 The search strategy summary

\begin{tabular}{ll}
\hline Items & Specification \\
\hline Date of search (specified to date, month and year) & $1999-2021$ \\
Databases and other sources searched & CNKI and VIP databases \\
Search terms used (including MeSH and free text search terms and filters) & Wound repair; natural products; skin; scar \\
& formation \\
Timeframe & 1999-2021 \\
Inclusion and exclusion criteria (study type, language restrictions etc.) & Related to wound repair \\
$\begin{array}{l}\text { Selection process (who conducted the selection, whether it was conducted independently, } \\
\text { how consensus was obtained, etc.) }\end{array}$ & $\begin{array}{l}\text { Xiaoping Wan conducted data search with } \\
\text { the assistance of other authors }\end{array}$ \\
Any additional considerations, if applicable & None \\
\hline
\end{tabular}

and then recognize intracellular specific receptors after being taken up to induce ROS and apoptosis and, consequently, bacteriostasis $(15,16)$. For example, resveratrol can effectively inhibit pathogenic fungi and bacteria in human skin. It is a plant defensin produced after stimulation of pathogenic microorganisms (such as fungi and bacteria) or environmental deterioration (such as ultraviolet light) (17). In addition, resveratrol can inhibit inflammation. Specifically, resveratrol can regulate the expression of inflammatory cytokines and chemokines through a mechanism closely related to NF-kB and AP-1 (18) and can inhibit lipopolysaccharide-activated macrophage inducible nitric oxide synthase and, therefore, inhibit the production of the proinflammatory factor nitric oxide. After the skin is injured, suppuration often occurs due to bacterial infections, but the condition can be improved by different degrees through treatment with Veratrum extraction (1:4) (19).

\section{Inbibiting scar fibroblast growth}

Skin wounds are prone to cause functional disturbances during the healing process and ultimately scar formation (20). Fibroblasts are effector cells in scar formation during wound healing. Studies have found that margarita liquid acts on human skin scar fibroblasts; a higher concentration of margarita liquid at a higher concentration can achieve higher inhibition and apoptosis rates of fibroblasts (21). Hirudin also has a significant inhibitory effect on skin fibroblasts in a concentration-dependent manner (22). By using a scar model in the rabbit ear, the group treated with hirudin ointment showed smaller fibroblasts and decreased cell bodies, indicating that hirudin inhibited the growth of scar fibroblasts and promoted apoptosis. Additionally, arteannuin and artesunate can inhibit the growth of skin scar fibroblasts cultured in vitro (23). Ren et al. proved that Chinese galls and centipedes could inhibit the proliferation of fibroblasts and collagen synthesis, significantly affecting the morphology and ultrastructure of fibroblasts and ultimately inhibiting scar formation after wound healing (24).

\section{Stimulating the expression of cell growth factors}

Transforming growth factor $\beta$ (TGF- $\beta$ ) shows a close relation with wound healing. In the early stage of wound healing, TGF- $\beta$ can promote the expression of key factors, such as the ECM protein fibronectin, type I and III collagen, and vascular endothelial growth factor (25). Among the TGF- $\beta$ family, TGF- $\beta 1$ can stimulate fibroblast contraction to promote wound healing (26). Some studies have confirmed that in a model of wound repair, powder medicine composed of hairyvein agrimonia herb, lotus root, frankincense and cattail pollen can regulate the TGF- $\beta 1$ signaling pathway to markedly increase TGF- $\beta 1$ mRNA expression, promote wound healing, and consequently reduce scar formation (27).

Basic fibroblast growth factor (bFGF) is a crucial link in the repair process of tissue injury. It can promote fibroblast proliferation, neovascularization, synthesis of hyaluronic acid in skin fibroblasts, and accumulation of leukocytes at the inflammatory site. bFGF has been widely recognized in clinical practice and used to promote wound healing and scar tissue healing (28). Additionally, hirudin has been proven to significantly downregulate TGF- $\beta 1 \mathrm{mRNA}$ and protein levels while upregulating bFGF mRNA and protein levels, thereby inhibiting scar formation after wound repair (29). 


\section{Promoting the expression of fibronectin}

It has been reported that in a rat model of wound repair, fibronectin expression is significantly increased by the water-in-oil cream "Shengfuling" made from 80 traditional Chinese herbal components, such as raw rhubarb (da huang), rhizoma coptidis (huang lian), Radix Angelicae Sinensis (dang gui), Semen Persicae (tao ren), Rhizoma Ligustici Chuanxiong (chuan xiong), frankincense (ru xiang), myrrh (mo yao), sesame oil, and span (30). The above findings suggested that Shengfuling could promote fibronectin expression in the wound, thereby repairing the wound and reducing scar formation.

\section{Inbibiting platelet-derived growth factor (PDGF)}

According to existing studies, PDGF is involved in wound repair by promoting the proliferation and chemotaxis of fibroblasts and stimulating fibronectin synthesis. It also has a regulatory effect on collagen synthesis and decomposition and promotes scar formation. Some researchers have determined that tetrandrine inhibits PDGF, TGF $\beta$ induced proliferation, and collagen synthesis in human hypertrophic scar fibroblasts using $3 \mathrm{H}-\mathrm{TdR}$ and $3 \mathrm{H}$-proline incorporation (31).

\section{Inbibiting the expression of connective tissue growth factor (CTGF)}

CTGF, also known as CCN family protein 2, is a cytoplasmic protein that is vital in tissue development and remodeling. CTGF is rarely expressed in normal adult tissues but is significantly upregulated in fibrotic tissues and increases during wound healing (32). Studies have shown that CTGF is induced by TGF- $\beta 1$ and is a downstream regulator of TGF- $\beta 1$. CTGF is involved in keloid pathogenesis by promoting collagen synthesis and deposition, which subsequently leads to a persistent fibrotic response (33). Additionally, curcumin can reduce CTGF protein and mRNA expression in keloid fibroblasts, suggesting that curcumin can inhibit collagen synthesis, and the mechanism may be related to the inhibition of CTGF expression by curcumin (34).

\section{Increasing the production of ECM}

The ECM includes collagen, fibronectin, matrix metalloproteinases, glycosaminoglycan and other components. The ECM produces beneficial cells and proteins that contribute to wound repair (35). Among them, matrix metalloproteinases can degrade the components of ECM, remove damaged proteins and temporary ECM in inflammatory stage, degrade capillary basement membrane in proliferative stage, shrink and reshape tissue in remodeling stage, and participate in cell migration and angiogenesis (36). Opuntia extract, in a rabbit ear model of scarring, can decrease collagen I expression and promote MMP-1 expression of collagen III in hypertrophic scar tissue, thereby reducing scar hyperplasia after wound repair and promoting the softening and absorption of the formed hypertrophic scar tissue (37). Curcumin can also reduce the expression of procollagen types I and III in keloid fibroblasts and, therefore, decrease scar production in keloids $(35,38)$. Additionally, by using a nude mouse model of hypertrophic scarring, onion extract and quercetin were shown to significantly increase MMP-1 expression and affect the ECM, thereby reducing scar formation in wound repair (39).

\section{Effects of common natural products on wound repair}

\section{Propolis for wound (burned) tissue}

Classical wound repair, by definition, is divided into the hemostasis phase, inflammatory phase, proliferative phase and remodeling phase $(40,41)$. These four phases overlap rather than strictly separate in time. The whole process is accomplished under the close coordination of various types of repair cells, cytokines, ECM molecules, and some proteolytic enzymes. Among the various factors that affect wound repair, the inflammatory response, bacterial infection and oxidative damage are three critical factors. Therefore, it has been suggested that the anti-inflammatory, antibacterial and antioxidant activities of propolis are reasons for its promotion of tissue regeneration and wound repair (42).

A study (43) stated that propolis is closely related to chondroitin/dermatan sulfate and hyaluronic acid accumulation during the repair of burn wounds. Propolis can accelerate tissue repair by stimulating the accumulation of glycosaminoglycans required for granulation tissue growth and for closing the injured site. Moreover, by accelerating chondroitin/dermatan sulfate structural adjustment, propolis is allowed to positively affect tissue repair in combination with growth factors. Some studies (44) have found that propolis and its active components are 
able to upregulate the production of TGF- $\beta 1$ in human peripheral blood mononuclear cells (PBMCs) and $\mathrm{T}$ lymphocytes, and TGF- $\beta 1$ is an important cytokine involved in fibroblast proliferation and collagen secretion (45-48). Accordingly, it was suggested that propolis may repair wound tissues by affecting the synthesis of cytokines involved in ECM production, such as TGF- $\beta 1$ and fibroblast growth factor (FGF).

\section{Effects of aloe on skin wound repair}

Clinically, antibiotic ointments such as erythromycin and bactroban are the main treatment for skin wounds, but due to the increase in drug-resistant strains or a narrow antibacterial spectrum, secondary infections occur from time to time; oral antibiotics cause severe side effects. In addition, FGF, which has a definite effect on wound repair, has no anti-infective effect and is expensive and therefore difficult to popularize. In contrast, aloe can not only inhibit bacterial reproduction and prevent posttraumatic infections but can also have a strong vitamin D-like effect and improve local blood circulation. With natural moisturizing properties caused by polysaccharides and monosaccharides in aloe and with a natural gel state, the active ingredients of aloe are more likely to penetrate the skin and be absorbed by tissues. According to clinical trials, aloe combined with a laser method reduced wound scab formation time and healing time (41). Aloe can reduce the expression of inflammatory factors and therefore relieve local redness, swelling, warmth and pain (49). Additionally, aloe can stimulate the tissue to secrete TNF- $\alpha$, thus improving the anti-infective ability of local tissue; promoting the proliferation and differentiation of fibroblasts, endothelial cells and epidermal cells; inducing the proliferation of capillaries; and consequently improving wound microcirculation and contributing to wound healing (50).

\section{Effect of Polygonum cuspidatum on skin wound repair}

Symptoms such as multiple organ dysfunction, inflammatory response, and sepsis will occur in response to trauma (51), and Polygonum cuspidatum has analgesic, heat-clearing, and antioxidant effects $(52,53)$. Some studies have researched the effect of Polygonum cuspidatum extract on wound healing in rats and found its wound healing activity. The mechanism is related to an increase in fibroblasts and hair follicle cells and a decrease in inflammatory cells (54). Polydatin, the main component of Polygonum cuspidatum, promotes the healing of ulcer wounds in type 2 diabetic mice by promoting fibroblast chemotaxis (55). In addition, wet compression with a compound Polygonum cuspidatum solution for healing sores, a Chinese traditional medicine prescription with Polygonum cuspidatum as the sovereign drug, can treat chronic refractory ulcers, showing a high effective rate without adverse effects (56). The decoction for clearing heat and promoting diuresis (Qingre Lishi decoction), a Chinese herbal compound with Polygonum cuspidatum as the sovereign drug, can effectively promote epithelial cell crawling, accelerate the regeneration of various components in granulation tissue, inhibit the inflammatory response, and thus promote wound healing (57). Collectively, Polygonum cuspidatum has great potential in repairing skin wounds.

\section{Prospects}

The efficacy of natural products has been recognized in the clinic and has broad research prospects, but the components of natural products are complex and have the characteristics of multiple targets and multiple links, hence the need for in-depth study. To fully combine the pharmacology of traditional Chinese medicine, future studies should be indepth on the mechanism of natural products and compound drugs in wound repair and on animal experiments and dosage form modification. The purpose here is to screen and develop drugs to reduce scar hyperplasia with exact effects and fewer side effects. Proteolysis by proteolytic enzymes, such as plasmin, matrix metalloproteinases, and their activators and inhibitors, plays a critical role in wound repair. Some keratinocytes often express some matrix metalloproteinases and plasminogen activators $(58,59)$, thus promoting the hydrolysis of components such as fibrin in blood clots to facilitate migration. Proteolytic enzymes produced by inflammatory reactions can degrade denatured proteins and tissues; however, excessive enzymolysis is not conducive to the deposition of new matrix and hinders the progress of repair. Therefore, whether and how natural products affect the expression of proteolytic enzymes also need to be further explored.

\section{Acknowledgments}

Funding: None.

\section{Footnote}

Reporting Checklist: The authors have completed the 
Narrative Review reporting checklist. Available at https:// atm.amegroups.com/article/view/10.21037/atm-21-7046/rc

Conflicts of Interest: All authors have completed the ICMJE uniform disclosure form (available at https://atm. amegroups.com/article/view/10.21037/atm-21-7046/coif). The authors have no conflicts of interest to declare.

Ethical Statement: The authors are accountable for all aspects of the work in ensuring that questions related to the accuracy or integrity of any part of the work are appropriately investigated and resolved.

Open Access Statement: This is an Open Access article distributed in accordance with the Creative Commons Attribution-NonCommercial-NoDerivs 4.0 International License (CC BY-NC-ND 4.0), which permits the noncommercial replication and distribution of the article with the strict proviso that no changes or edits are made and the original work is properly cited (including links to both the formal publication through the relevant DOI and the license). See: https://creativecommons.org/licenses/by-nc-nd/4.0/.

\section{References}

1. Das $\mathrm{S}$, Baker AB. Biomaterials and Nanotherapeutics for Enhancing Skin Wound Healing. Front Bioeng Biotechnol 2016;4:82.

2. Zhao N, Liu DQ, Wang GJ, et al. Role of autophagy during cutaneous wound healing in mice. Journal of third military medical university 2019;41:25-32.

3. Subramaniam T, Fauzi MB, Lokanathan Y, et al. The Role of Calcium in Wound Healing. Int J Mol Sci 2021;22:6486.

4. Tang MJ, Yuan T, OuYang YP, et al. Advances in research of platelet-rich plasma in improving chronic wound repair. Journal of Clinical Orthopaedics 2009;2:229-31.

5. Farstvedt E, Stashak TS, Othic A. Update on topical wound medications. Clinical Techniques in Equine Practice 2004;3:164-72.

6. Chen J, Han C M, Lin X W, et al. Effect of silver nanoparticle dressing on second degree burn wound. Chinese Journal of Surgery 2006;44:50-2.

7. Olczyk P, Wisowski G, Komosinska-Vassev K, et al. Propolis Modifies Collagen Types I and III Accumulation in the Matrix of Burnt Tissue. Evid Based Complement Alternat Med 2013;2013:423809.

8. Almeida MS, Cabral KM, Kurtenbach E, et al. Solution structure of Pisum sativum defensin 1 by high resolution
NMR: plant defensins, identical backbone with different mechanisms of action. J Mol Biol 2002;315:749-57.

9. Liu YJ, Cheng CS, Lai SM, et al. Solution structure of the plant defensin $\operatorname{VrD} 1$ from mung bean and its possible role in insecticidal activity against bruchids. Proteins 2006;63:777-86.

10. Ye XY, Ng TB, Tsang PW, et al. Isolation of a homodimeric lectin with antifungal and antiviral activities from red kidney bean (Phaseolus vulgaris) seeds. J Protein Chem 2001;20:367-75.

11. Guimarães NS, Mello JC, Paiva JS, et al. Baccharis dracunculifolia, the main source of green propolis, exhibits potent antioxidant activity and prevents oxidative mitochondrial damage. Food Chem Toxicol 2012;50:1091-7.

12. Hu X, Lin Q L. Healthcare Function and Application Process of Propolis. Academic Periodical of Farm Products Processing 2007;5:31-4.

13. Pastor JM, Salvador M, Argandoña $M$, et al. Ectoines in cell stress protection: uses and biotechnological production. Biotechnol Adv 2010;28:782-801.

14. Kunte HJ, Lentzen G, Galinski E. Industrial Production of the Cell Protectant Ectoine: Protection Mechanisms, Processes, and Products. Curr Biotechnol 2014. doi: 10.2174/22115501113026660037.

15. Wilmes M, Cammue BP, Sahl HG, et al. Antibiotic activities of host defense peptides: more to it than lipid bilayer perturbation. Nat Prod Rep 2011;28:1350-8.

16. De Brucker K, Cammue BP, Thevissen K. Apoptosisinducing antifungal peptides and proteins. Biochem Soc Trans 2011;39:1527-32.

17. Ding Y, Fan H. Research progress on anti-inflammatory effects of resveratrol, an active component derived from natural plants. West China Medical Journal 2008;1:199-200.

18. Cai YL, Chen JC. Optimization by response surface analysis of the extraction of trans-resveratrol from Polygonum cuspidatum and a study of its antibacterial effects. Journal of Beijing University of Chemical Technology (Natural Science Edition) 2010;37:108-12.

19. Zhao Y, Lu GC, Zhang WD, et al. Research progress in Pharmacology and Toxicology of Veratrum alkaloids. Traditional Chinese Drug Research and Clinical Pharmacology 2008;3:240-2.

20. Sun Z, Li S, Cao C, et al. shRNA targeting SFRP2 promotes the apoptosis of hypertrophic scar fibroblast. Mol Cell Biochem 2011;352:25-33.

21. Nong XL, Chen H, Chen SH, et al. Inhibition of human scar fibroblast cells growth by margarita liquid. Journal of Clinical Rehabilitative Tissue Engineering Research 
2009;46:9088-91.

22. Nong XL, Chen H, Li JQ, et al. In vitro and In vivo Inhibition of Skin Scar by Hirudin. Natural Product Research and Development 2013;12:1638-43.

23. Nong X L, Chen H, Chen SH, et al. Growth inhibition of fibroblasts derived from human by arteannuin and artesunate in vitro. Journal of Guangxi Medical University 2009;26:202-5.

24. Ren LH, Hao LJ, Duan GX, et al. Effect of gallnut and centipede on proliferation and collagen synthesis of the keloid-derived fibroblasts. Journal of Practical Aesthetic and Plastic Surgery 2003;6:324-7.

25. Barrientos S, Stojadinovic O, Golinko MS, et al. Growth factors and cytokines in wound healing. Wound Repair Regen 2008;16:585-601.

26. Pakyari M, Farrokhi A, Maharlooei MK, et al. Critical Role of Transforming Growth Factor Beta in Different Phases of Wound Healing. Adv Wound Care (New Rochelle) 2013;2:215-24.

27. Hou Q, He WJ, Hao HJ, et al. The four-herb Chinese medicine ANBP enhances wound healing and inhibits scar formation via bidirectional regulation of transformation growth factor pathway. PLoS One 2014;9:e112274.

28. Akita S, Akino K, Hirano A. Basic Fibroblast Growth Factor in Scarless Wound Healing. Adv Wound Care (New Rochelle) 2013;2:44-9.

29. Guo R, Nong XL, Deng L, et al. Effects of Hirudin on expression of bFGF, TGF $\beta$ _1 in dermal hypertrophic scar fibroblasts. Chinese Journal of Aesthetic Medicine 2011;20:614-7.

30. Pan JX, Wang LQ, Zhang SS, et al. Experimental Study of Shengfuling in Rat Epidermal Growth Factor and Fibronectin. Chinese Journal of Traditional Medical Traumatology \& Orthopedics 2012;2:6-7.

31. Liu DW, Li GH, Zou P, et al. Inhibitory effect of tetrandrine on the proliferation and collagen synthesis of human scar-derived fibroblasts stimulated by PDGF and TGF- $\beta$. Pharmacology and Clinics of Chinese Materia Medica 2004;4:10-11.

32. Cicha I, Goppelt-Struebe M. Connective tissue growth factor: context-dependent functions and mechanisms of regulation. Biofactors 2009;35:200-8.

33. Jurzak M, Adamczyk K, Antończak P, et al. Evaluation of genistein ability to modulate CTGF mRNA/protein expression, genes expression of TGF $\beta$ isoforms and expression of selected genes regulating cell cycle in keloid fibroblasts in vitro. Acta Pol Pharm 2014;71:972-86.

34. Hu XL, Hu DH, Han YB, et al. Effect of curcumin on the collagen synthesis of keloid fibroblasts. Journal of Clinical Rehabilitative Tissue Engineering Research 2008;12:9024-7.

35. Xue M, Jackson CJ. Extracellular Matrix Reorganization During Wound Healing and Its Impact on Abnormal Scarring. Adv Wound Care (New Rochelle) 2015;4:119-36.

36. He X J, Liu QW, Chen J. Research progress of matrix metalloproteinases in chronic wound. Journal of Medical Research 2021;50:155-7.

37. Fang Q, Huang C, You C, et al. Opuntia Extract Reduces Scar Formation in Rabbit Ear Model: A Randomized Controlled Study. Int J Low Extrem Wounds 2015;14:343-52.

38. Fang Q, Ma SL, Dong XL. The effect of the extract of opuntia on the expression of type I and III collagen and MMP-1 of hypertrophic scar in rabbits ears. Journal of Xinjiang Medical University 2007;30:568-71.

39. Cho JW, Cho SY, Lee SR, et al. Onion extract and quercetin induce matrix metalloproteinase- 1 in vitro and in vivo. Int $\mathrm{J}$ Mol Med 2010;25:347-52.

40. Gurtner GC, Werner S, Barrandon Y, et al. Wound repair and regeneration. Nature 2008;453:314-21.

41. Li L, Wang L, Li Y, et al. The effect of aloe glue on local inflammatory reaction caused by laser therapy. Journal of Clinical Dermatology 2003;(12):739-40.

42. Ramos FNR, Miranda JL. Propolis: a review of its antiinflammatory and healing actions. J Venom Anim Toxins incl Trop 2007. doi: 10.1590/S1678-91992007000400002

43. Olczyk P, Komosinska-Vassev K, Winsz-Szczotka K, et al. Propolis induces chondroitin/dermatan sulphate and hyaluronic Acid accumulation in the skin of burned wound. Evid Based Complement Alternat Med 2013;2013:290675.

44. Ansorge S, Reinhold D, Lendeckel U. Propolis and some of its constituents down-regulate DNA synthesis and inflammatory cytokine production but induce TGF-beta1 production of human immune cells. Z Naturforsch C J Biosci 2003;58:580-9.

45. Gressner AM, Weiskirchen R, Breitkopf K, et al. Roles of TGF-beta in hepatic fibrosis. Front Biosci 2002;7:d793-807.

46. Schiller M, Javelaud D, Mauviel A. TGF-beta-induced SMAD signaling and gene regulation: consequences for extracellular matrix remodeling and wound healing. J Dermatol Sci 2004;35:83-92.

47. Leask A, Abraham DJ. TGF-beta signaling and the fibrotic response. FASEB J 2004;18:816-27.

48. Faler BJ, Macsata RA, Plummer D, et al. Transforming growth factor-beta and wound healing. Perspect Vasc Surg Endovasc Ther 2006;18:55-62.

49. Qian ZS, Zhang CM, Niu GH. Changes of IL-6, IL$8, \mathrm{IL}-10, \mathrm{TNF}-\alpha$ and immunoglobulin of children with 
henoth-schonlein purpura. Medical Journal of Liaoning 2006;20:6-7.

50. Xuan ZY, Lu YQ, Liu DH, et al. Immunohistochemical expressions of IL-1 and VEGF in healing process of incised skin wounds in rats. Journal of Jilin University(Medicine Edition) 2007;3:460-3.

51. Olivares-Villagómez D, Van Kaer L. Intestinal Intraepithelial Lymphocytes: Sentinels of the Mucosal Barrier. Trends Immunol 2018;39:264-75.

52. Gao Y, Chen T, Lei X, et al. Neuroprotective effects of polydatin against mitochondrial-dependent apoptosis in the rat cerebral cortex following ischemia/reperfusion injury. Mol Med Rep 2016;14:5481-8.

53. Ye J, Piao H, Jiang J, et al. Polydatin inhibits mast cellmediated allergic inflammation by targeting PI3K/ Akt, MAPK, NF-кB and Nrf2/HO-1 pathways. Sci Rep 2017;7:11895.

54. Wu XB, Luo XQ, Gu SY, et al. The effects of Polygonum

Cite this article as: Wan X, Chen Y, Geng F, Sheng Y, Wang F, Guo J. Narrative review of the mechanism of natural products and scar formation in wound repair. Ann Transl Med 2022;10(4):236. doi: 10.21037/atm-21-7046 cuspidatum extract on wound healing in rats. J

Ethnopharmacol 2012;141:934-7.

55. Han YZ, Shen J, Wu LR, et al. Experimental study of polydatin on wound healing in type 2 diabetic of mice. The Chinese Journal of Clinical Pharmacology 2017;33:1934-7.

56. Shi LF. Compound Polygonum cuspidatum solution for healing sores in 160 cases with chronic refractory ulcers and pressure sores. Hebei Journal of Traditional Chinese Medicine 2012;34:609-10.

57. Yang HJ, Liu H. Effects of Chinese Herbal Compound on Wound Healing after Anorectal Surgery: A Study in SD

Rats. Chinese Archives of Traditional Chinese Medicine 2018;36:377-80.

58. Santoro MM, Gaudino G. Cellular and molecular facets of keratinocyte reepithelization during wound healing. Exp Cell Res 2005;304:274-86.

59. Singer AJ, Clark RA. Cutaneous wound healing. N Engl J Med 1999;341:738-46. 